\title{
Fluorescent Bioactive Corrole Grafted-Chitosan Films
}

Joana F. B. Barata, ${ }^{* \dagger, \S}$ Ricardo J. B. Pinto, ${ }^{\dagger}$ Vanda I. R. C. Vaz Serra, ${ }^{\star}{ }^{\star}$ Armando J. D. Silvestre ${ }^{\dagger}$

Tito Trindade, ${ }^{\dagger}$ Maria Graça P. M. S. Neves,${ }^{\S}$ José A. S. Cavaleiro, ${ }^{\S}$ Sara Daina, ${ }^{\Perp}$ Patrizia Sadocco, $\Perp$ and Carmen S. R. Freire*

${ }^{\dagger}$ Department of Chemistry-CICECO, and ${ }^{\S}$ Department of Chemistry-QOPNA, University of Aveiro, 3810-193 Aveiro, Portugal

${ }^{\ddagger}$ Centro Química Estrutural, Complexo I, Instituto Superior Té cnico, 1049-001 Lisboa, Portugal

"INNOVHUB -Divisione Carta, Piazza Leonardo Da Vinci, 16, 20133 Milan, Italy

\section{- Supporting Information -}

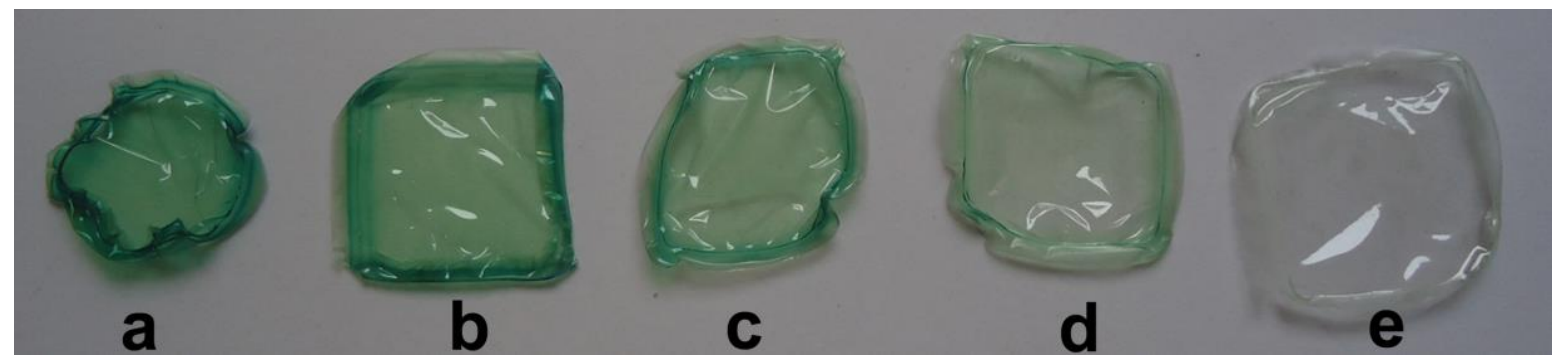

Figure S1. Digital photographs of chitosan/TPFC films prepared by direct mixture of the components with distinct TPFC amounts: a) 100, b) 75 , c) 50, d) 25 , and e) $10 \mu \mathrm{g}$. 

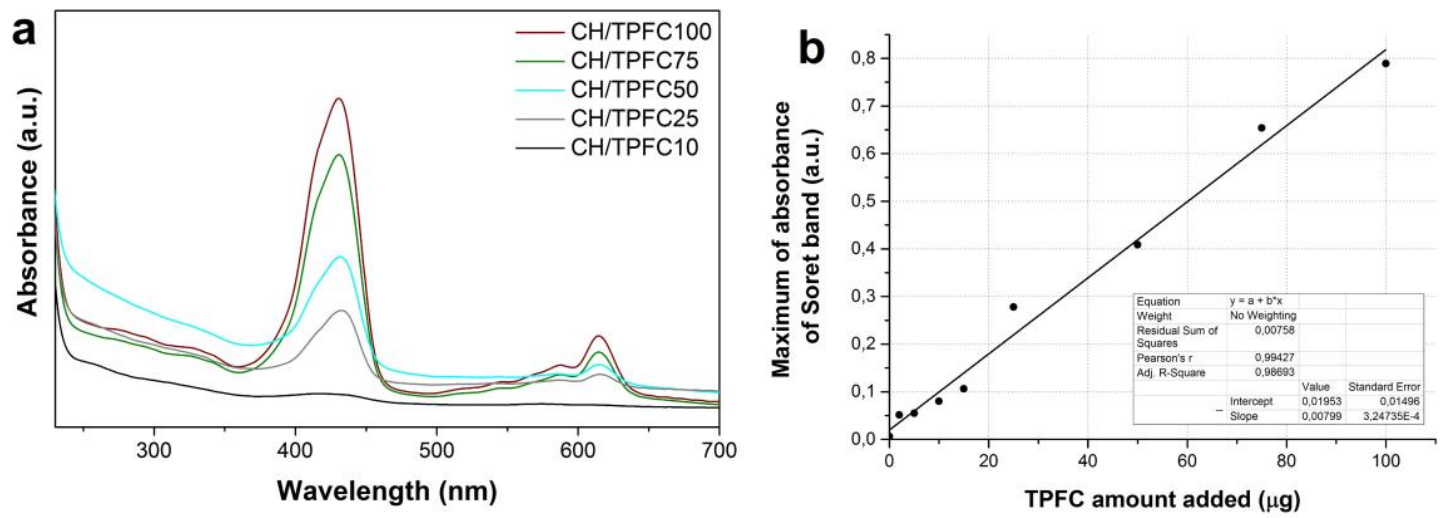

Figure S2. a) Optical spectra of CH/TPFC composites films prepared from direct mixture and b) plot of maximum of absorbance of Soret band vs TPFC amount added.

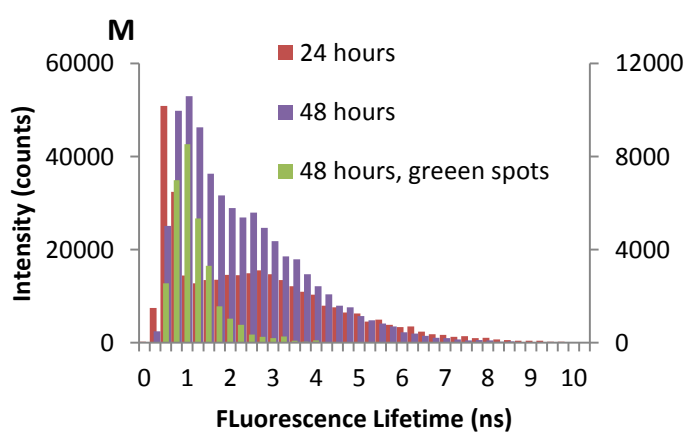

Figure S3 - (M) Lifetime histogram of representative images E and K of Figure 3. 


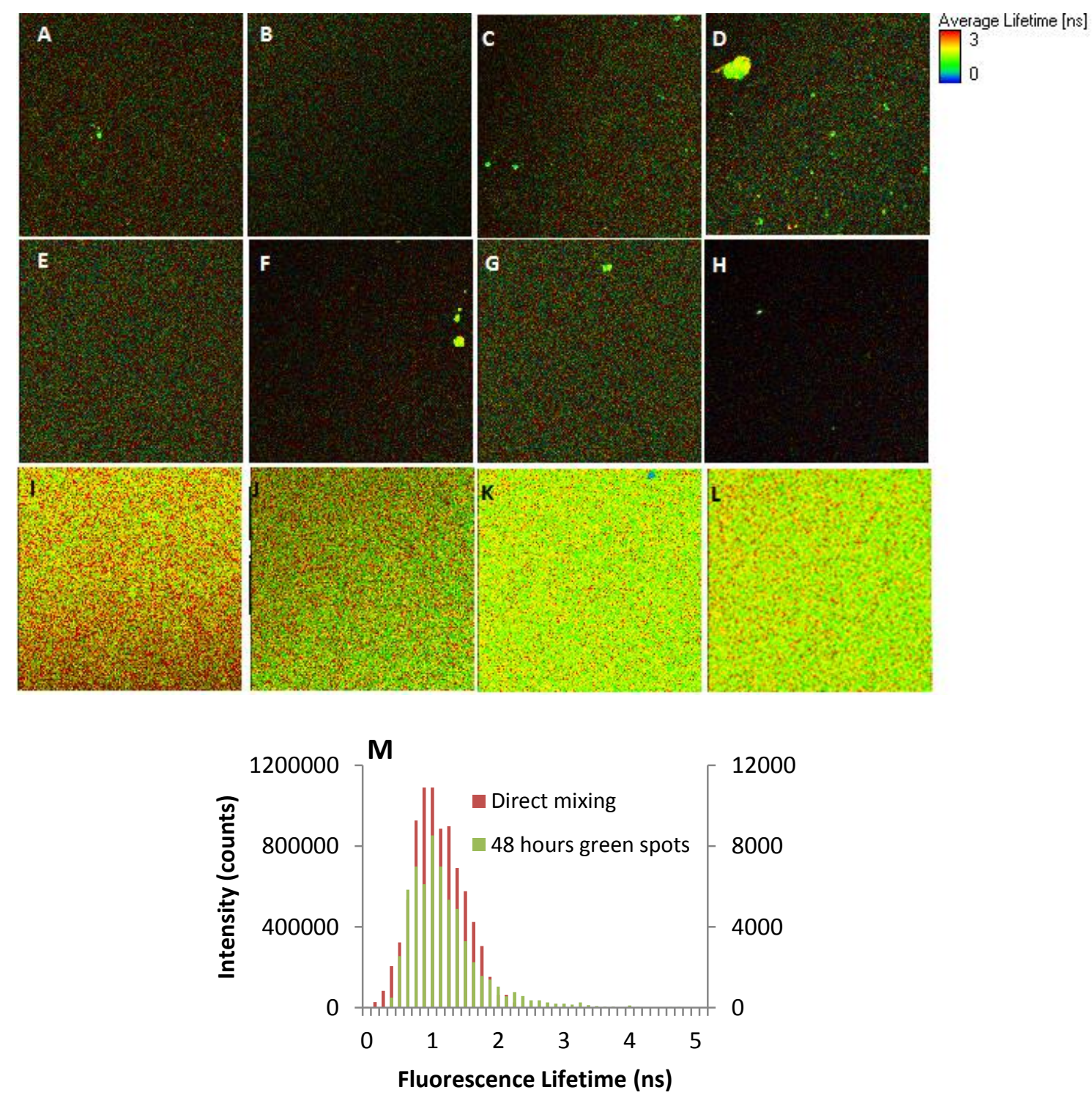

Figure S4. Fluorescence lifetime images obtained for corrol-chitosan films obtained by direct mixing (A-D) CH/TPFC10 (E-H) CH/TPFC25 (I-L) CH/TPFC500. (M) Lifetime histogram of representative images $\mathrm{K}$ and $\mathrm{CH} / \mathrm{TPFC} 48 \mathrm{~h}$. 


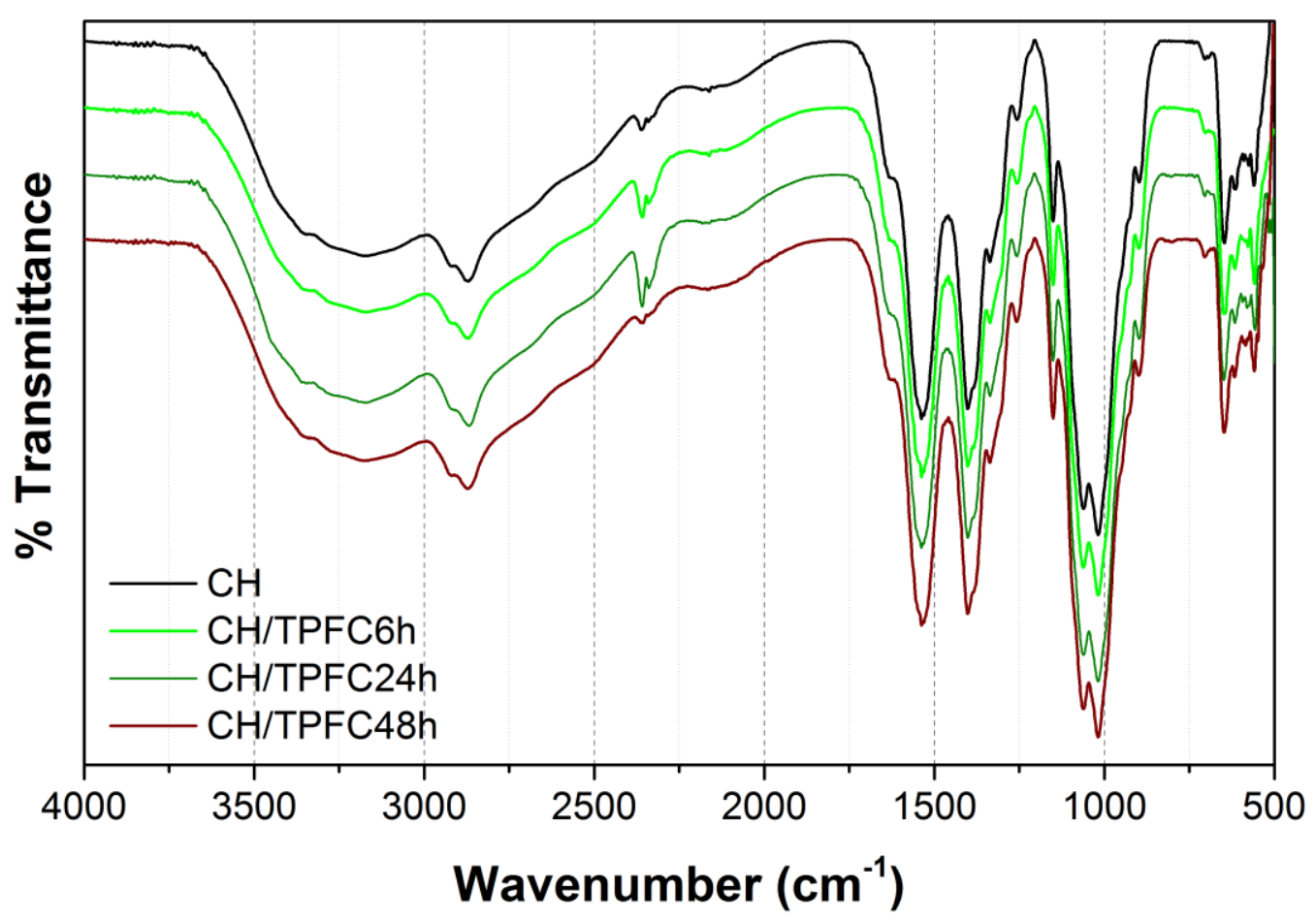

Figure S5. FTIR spectra of pristine chitosan and correspondent corrole grafted chitosan films. 

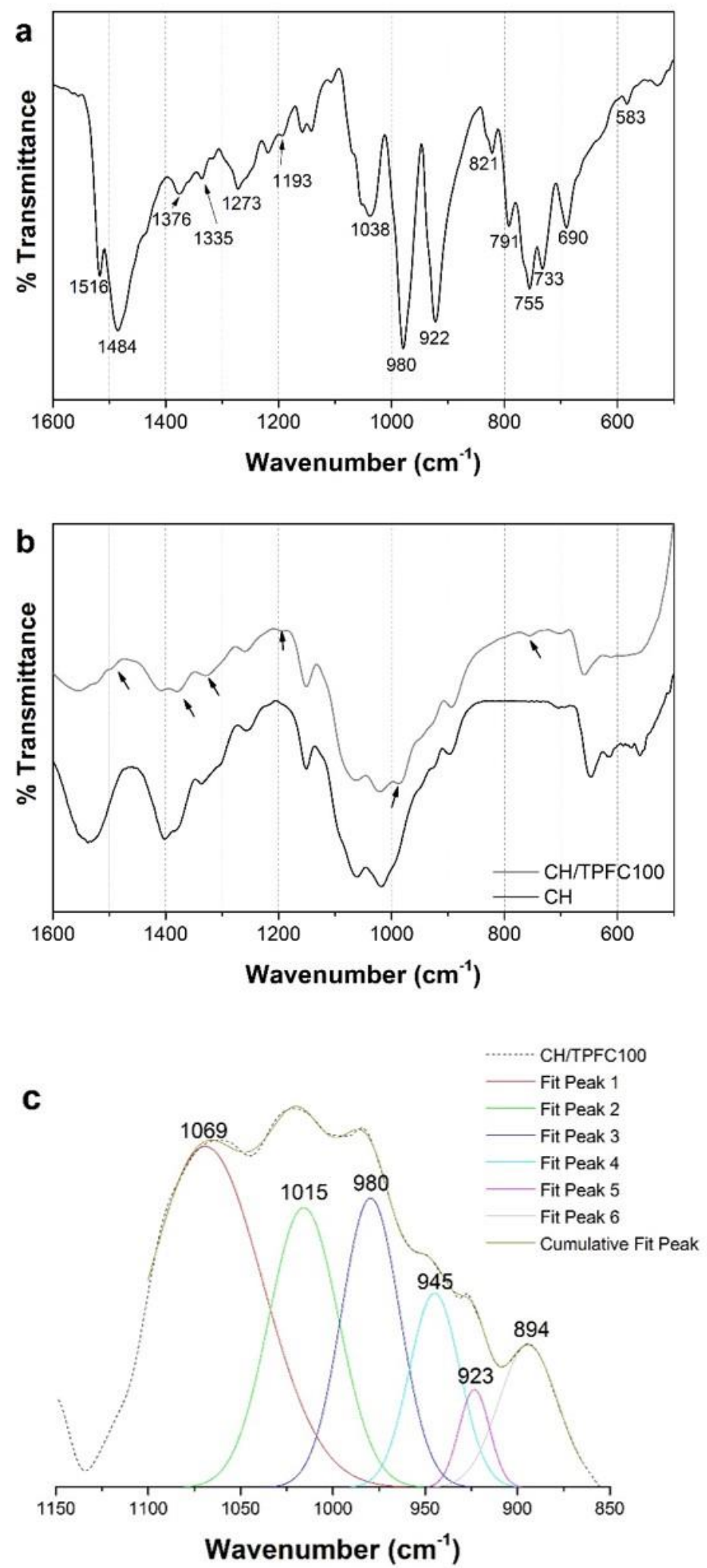

Figure. S6. FTIR spectra of a) pure TPFC, b) magnification of pristine $\mathrm{CH}$ and $\mathrm{CH} / \mathrm{TPFC} 100$ derivative film, and c) respective deconvolution of CH/TPFC showing their respective bands $\left(850-1150 \mathrm{~cm}^{-1}\right)$. 


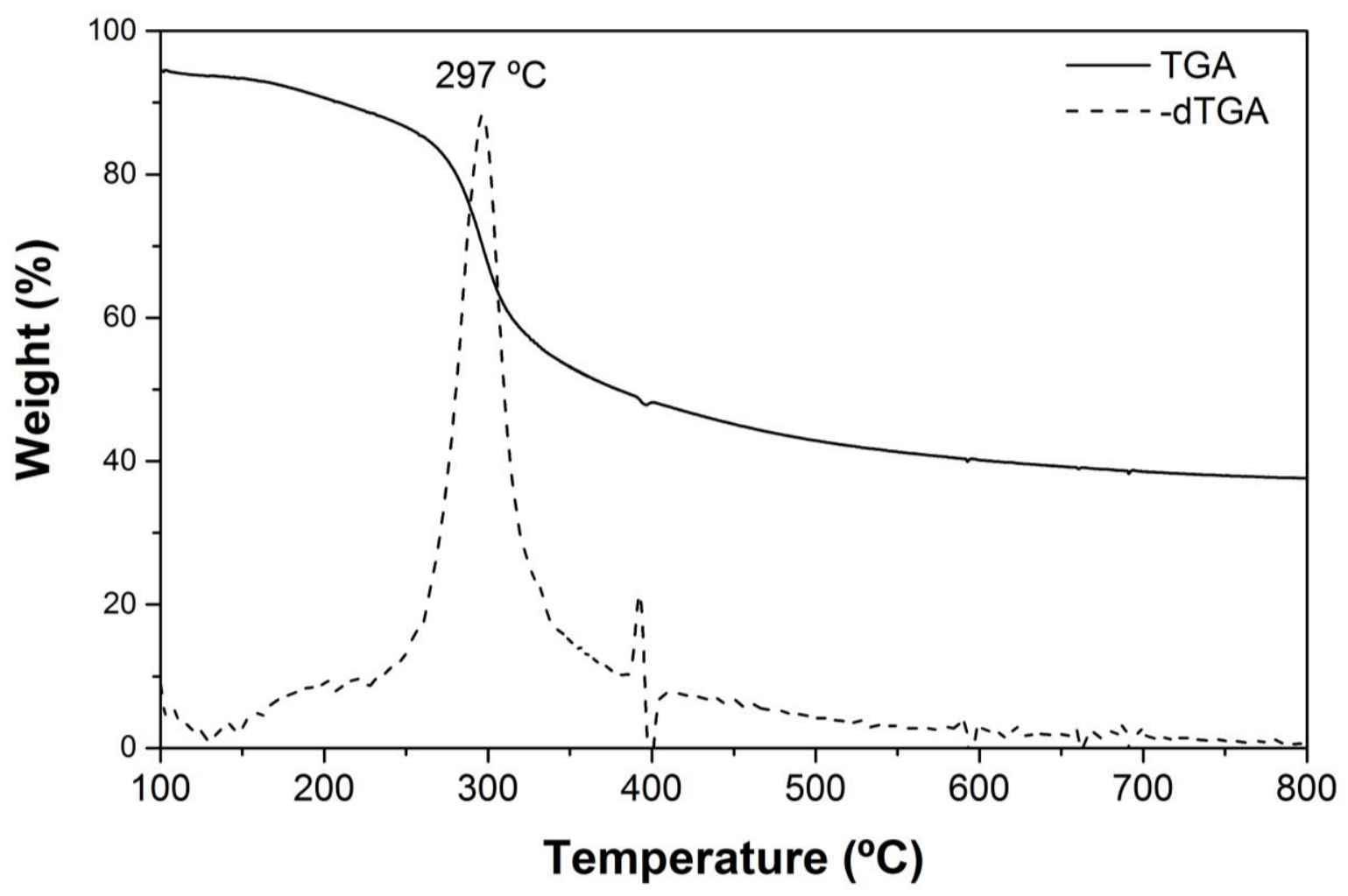

Figure. S7. Thermogravimetric and respective -dTGA curves of the sample CH/TPFC100. 


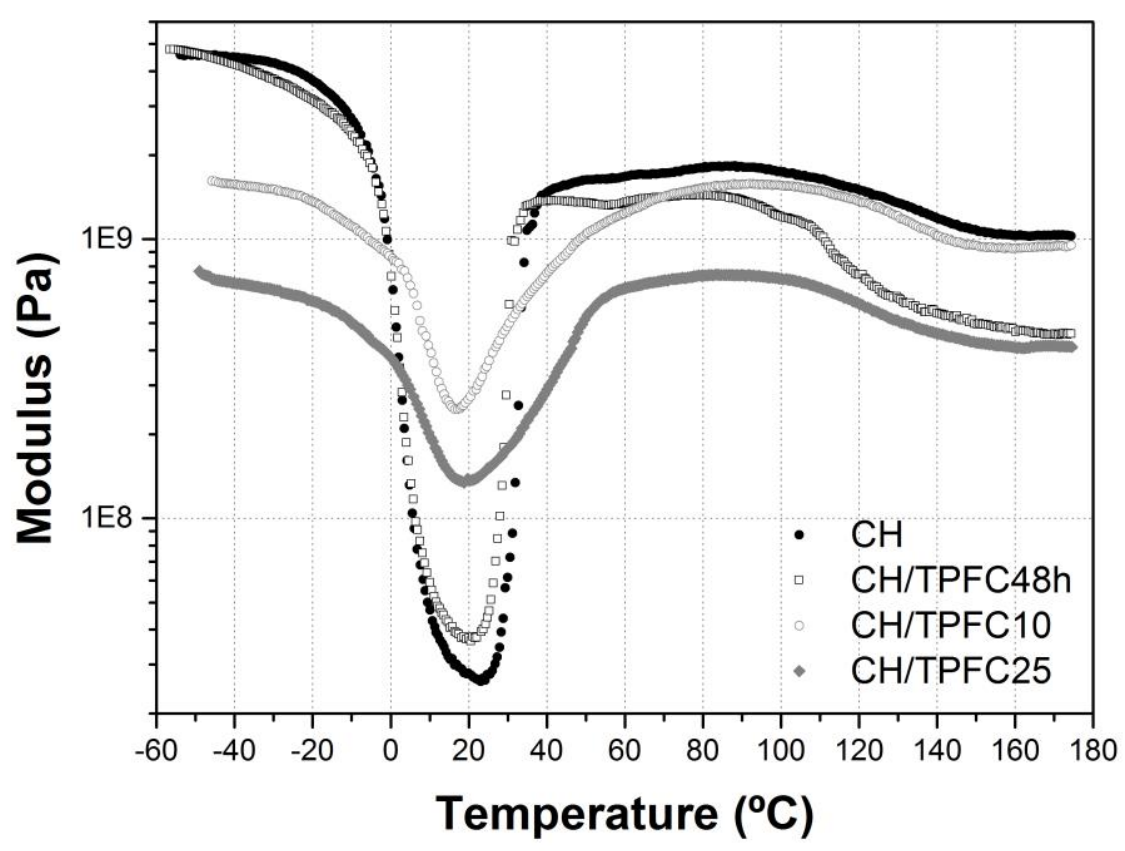

Figure. S8. Temperature dependency of the modulus of $\mathrm{CH}$ and $\mathrm{CH} / \mathrm{TPFC} 48 \mathrm{~h}$ films in comparison with the ones prepared by direct mixture (CH/TPFC10 and CH/TPFC25).

\section{S. aureus}

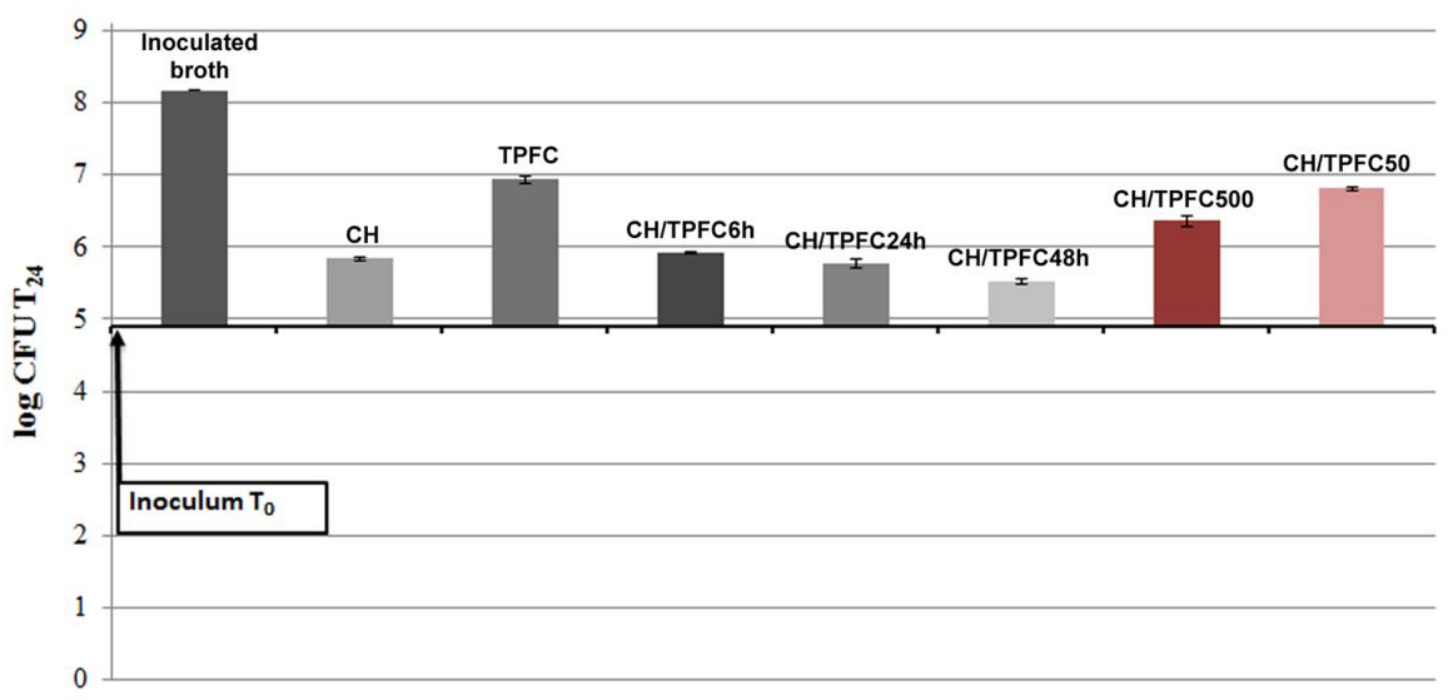

Figure. S9. Antibacterial activity of $\mathrm{CH}, \mathrm{TPFC}$, and chitosan/corrole derivatives against $S$. aureus.

The $\log$ CFU values were determined in the testing broth after $24 \mathrm{~h}$ contact time and were compared to those of pure $\mathrm{CH}$ and TPFC matrices. Horizontal dark line refers to the initial inoculum (log $\mathrm{CFU}$ at time 0). 
Table S1. Identification of all CH/TPFC films prepared by direct mixing. Thickness errors correspond to standard deviations $(\mathrm{SD}, \mathrm{n}=10)$.

\begin{tabular}{ccccc}
\hline Sample & CH & TPFC added & Thickness & Film weight \\
& $(\mathbf{m g})$ & $(\mu \mathrm{g})$ & $(\mu \mathrm{m})$ & $(\mathbf{m g})$ \\
\hline CH & 20 & - & $15.6 \pm 2.0$ & 22.4 \\
CH/TPFC10 & 20 & 10 & $14.7 \pm 2.1$ & 24.7 \\
CH/TPFC25 & 20 & 25 & $14.3 \pm 3.5$ & 24.7 \\
CH/TPFC50 & 20 & 50 & $14.8 \pm 1.6$ & 24.2 \\
CH/TPFC75 & 20 & 75 & $16.9 \pm 3.3$ & 27.5 \\
\hline CH/TPFC100 & 20 & 100 & $17.4 \pm 3.1$ & 25.1 \\
\hline CH/TPFC500 & 20 & 500 & $17.7 \pm 2.7$ & 24.8 \\
\hline & & & & \\
\hline
\end{tabular}

Table S2: Binding energies of C1s, O1s, N1s and F1s and bond assignments determined by XPS for CH, CH/TPFC100, CH/TPFC48h.

\begin{tabular}{|c|c|c|c|}
\hline & $\mathbf{C H}$ & CH/TPFC100 & CH/TPFC48h \\
\hline \multirow{4}{*}{ C1s } & \multirow{4}{*}{$\begin{array}{c}285.0 \mathrm{C}-\mathrm{C} ; \mathrm{C}-\mathrm{H} \\
286.7 \mathrm{C}-\mathrm{N} ; \mathrm{C}-\mathrm{O} \\
288.0 \mathrm{~N}-\mathrm{C}=\mathrm{O}\end{array}$} & 285.0 & 285.0 \\
\hline & & 286.8 & 286.7 \\
\hline & & 288.4 & 288.0 \\
\hline & & 289.8 C-F & $289.1 \mathrm{C}-\mathrm{F}$ \\
\hline N1s & $\begin{array}{c}399.6(\text { non-protonated } \mathrm{N} ; \mathrm{N}-\mathrm{C}, \mathrm{N}-\mathrm{C}=\mathrm{O}) \\
401.7(\text { protonated } \mathrm{N})\end{array}$ & $\begin{array}{c}\text { 399.8(non-protonated } \mathrm{N} ; \mathrm{N}=\mathrm{C} \\
\text { and pyrrolic iminic type } \\
400.6(\mathrm{C}-\mathrm{N} \text {, protonated } \mathrm{N} \text { and } \\
\text { pyrrolic aminic type }\end{array}$ & $\begin{array}{c}\text { 399.7 (non-protonated } \mathrm{N} ; \mathrm{N}=\mathrm{C} \\
\text { and pyrrolic iminic type) } \\
401.0 \text { (protonated } \mathrm{N} \text { and } \\
\text { pyrrolic aminic type) }\end{array}$ \\
\hline F1s & & $688.5 \mathrm{C}-\mathrm{F}$ & $688.8 \mathrm{C}-\mathrm{F}$ \\
\hline
\end{tabular}

